\title{
Research Paper \\ The Effects of Economic Shocks on Labor Market in Iran
}

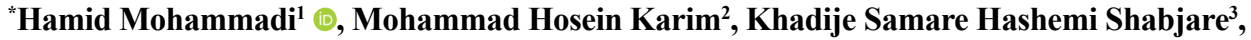 \\ Alireza Sargazi ${ }^{4}$ ()
}

1. Assistant Professor, Department of Agricultural Economics, Faculty of Agriculture, University of Zabol, Zabol, Iran.

2. Associate Professor, Department of Economics, Faculty of Economics, Kharazmi University, Tehran, Iran.

3. PhD. Student, Department of Agricultural Economics, Faculty of Agriculture, University of Zabol, Zabol, Iran.

4. Lecturer, Department of Agricultural Economics, Faculty of Agriculture, University of Zabol, Zabol, Iran.

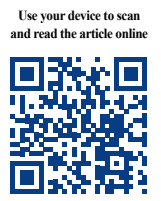

Crtation: Mohammadi, H., Hosein Karim, M., Samare Hashemi Shabjare, Kh., Sargazi, A. (2019). [The Effects of Economic Shocks on Labor Market in Iran (Persian)]. Quarterly Journal of the Macro and Strategic Policies, 7(2), 268-285. https://doi.org/10.32598/JMSP.7.2.268

ol' https://doi.org/10.32598/JMSP.7.2.268

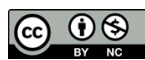

Received: 21 Feb 2017

Accepted: 22 Apr 2018

Available Online: 01 Apr 2019

Key words:

Efficiency, Wage,

Structural vector error correction model,

Labor force

\section{ABSTRACT}

The labor market is one of four major markets in the economy; it is important because of its unique features. In the present study, the long-term effects of various macroeconomic shocks on the unemployment rate have been investigated from 1974 to 2016 using the Structural Vector Error Correction Model (SVECM). Based on the estimated equation, the real wages have a direct relationship with efficiency and employment and an indirect relationship with the unemployment rate. Impulse response analysis showed that among the shocks, efficiency and supply shocks have a more substantial impact on unemployment so that the efficiency shocks reduce the unemployment rate in the long run and the positive labor supply shock leads to higher unemployment. According to the results of unemployment forecast of error variance decomposition, the shock of labor supply, efficiency, and labor demand are determinant factors of unemployment in the long run. But the most critical factor in unemployment is the supply shocks that their effect increases over time. JEL Classification: E24, J20, J31

* Corresponding Author:

Hamid Mohammadi, PhD.

Address: Department of Agricultural Economics, Faculty of Agriculture, University of Zabol, Zabol, Iran.

Tel: +98 (0917) 3141455

E-mail: hamidmohammadi1378@gmail.com 


\section{اثرات شوكهاى اقتصادى بر بازار نيروى كار در ايران}

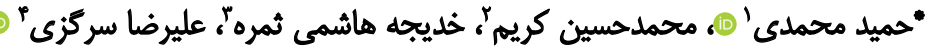

ا - استاديار كروه اقتصاد كشاورزى، دانشكده كثاورزى، دانشعاه زابل، زابل، ايران.

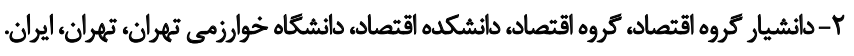

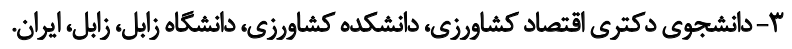
F - مربى كروه اقتصاد كشاورزى، دانشكده كشاورزى، دانشكاه زابل، زابل، ايران.

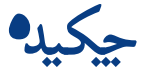

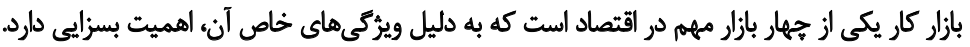

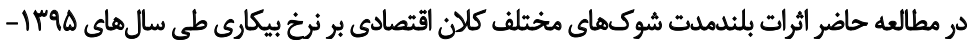

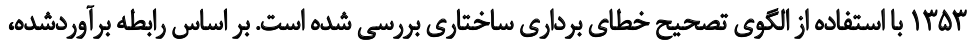

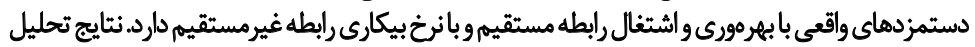

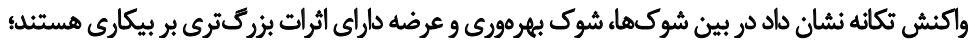

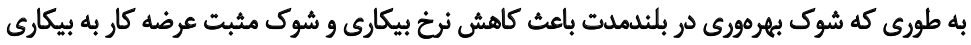

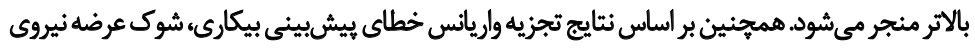

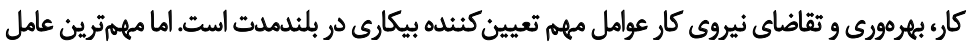

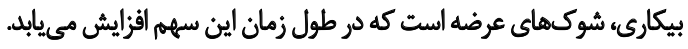

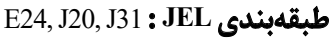

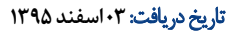

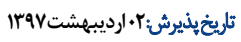

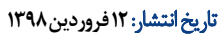

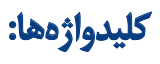

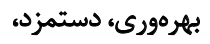

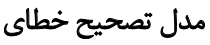
برودارى ساختارى، تمديح نيروى كار ماري

* نويسنده مسئول:

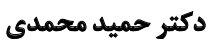

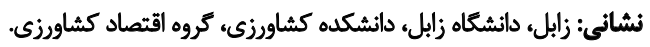
تلفي:

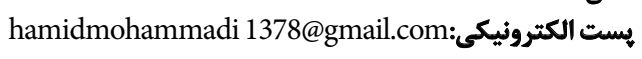




\section{dalo}

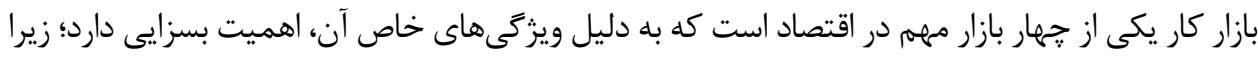

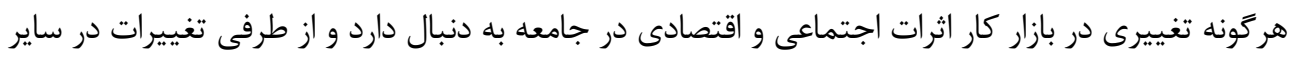

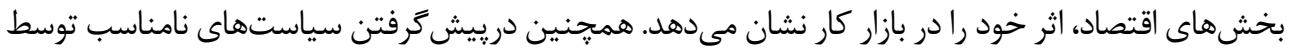

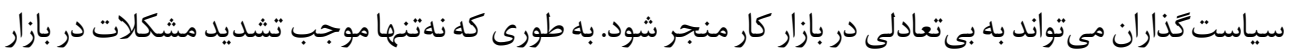

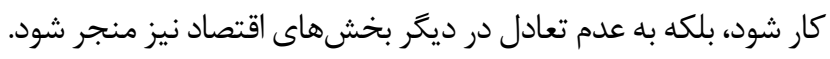

يكى از شاخصهاى كليدى و معروف بازار كار، بيكارى است كه نشاندهنده بخشى از نيروى كار جامعه است

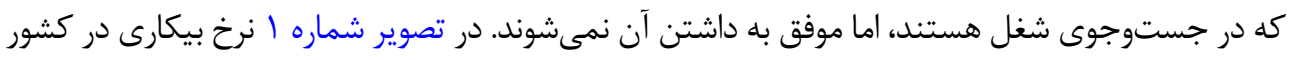

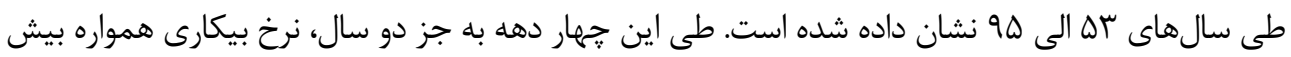

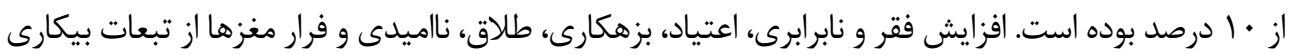

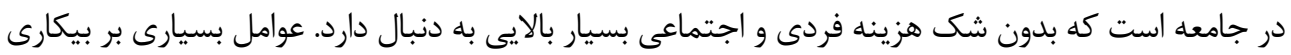

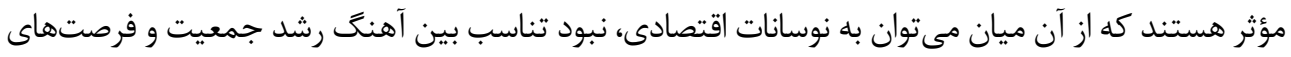

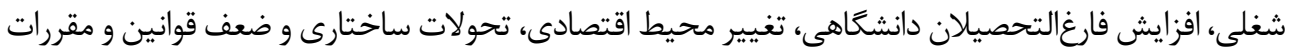
اشاره كرد.

امروزه يكى از دغدغههاى اصلى در كشور مسئله بيكارى است كه لزوماً به نوسانات فصلى و دورهاى اقتصاد

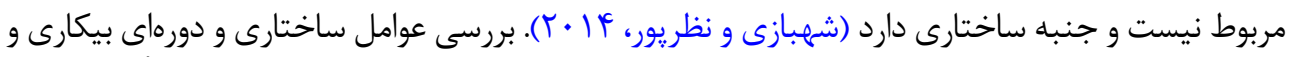

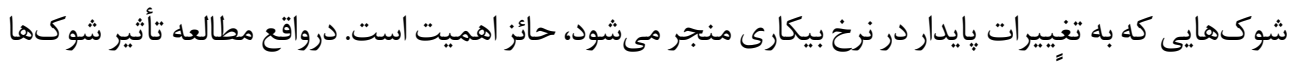

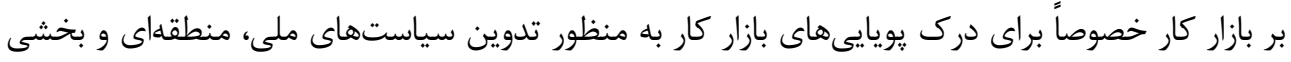

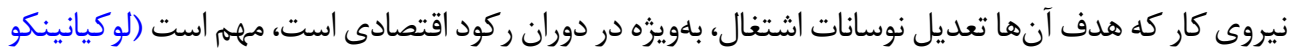

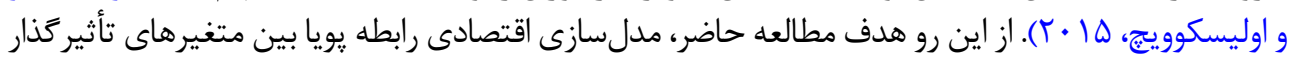
بر بازار كار بر اساس مدل تصحيح خطاى بردارى ساختارى و تجزيه و تحليل اثر شوكهاى مأى مؤثر بر بيكارى و و

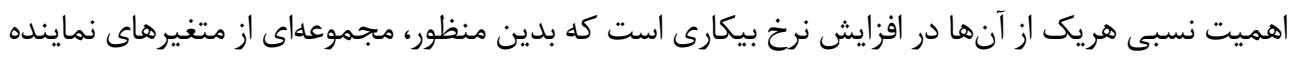

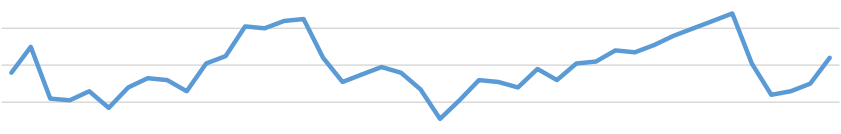

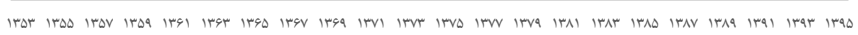

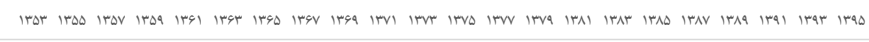


بازار نيروى كار در نظر كرفته شده و يك مدل ساده بازار كار اقتصاد كلان ايجاد شده است تا واكنش متغيرها

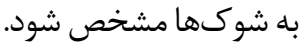

\section{1- ادبيات موضوع}

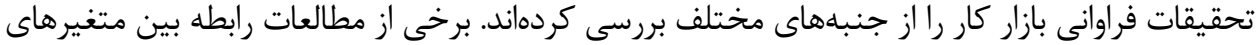

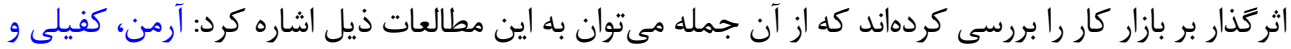

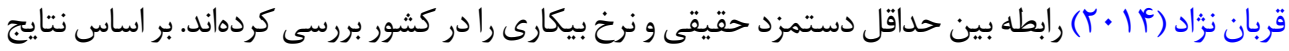

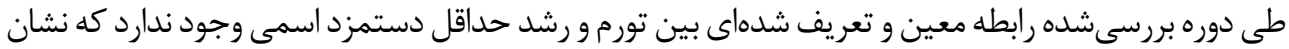

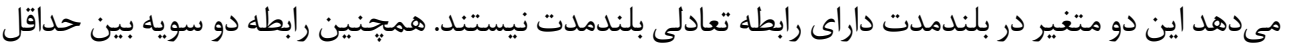

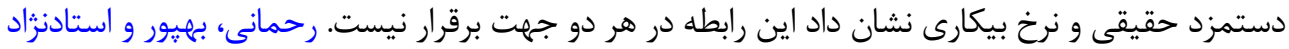

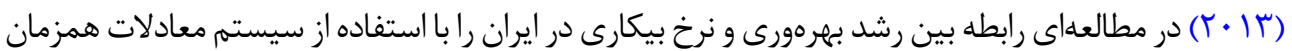

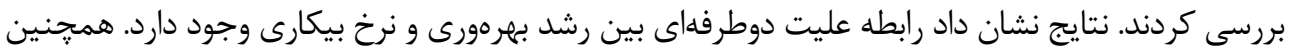

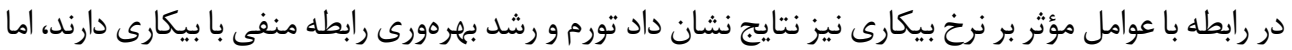

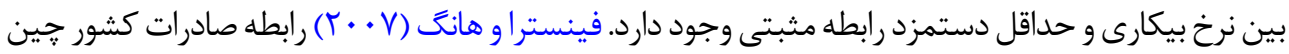

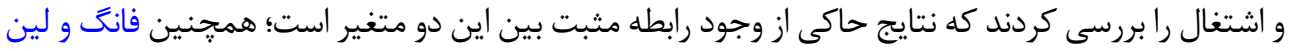

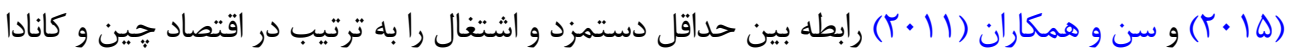

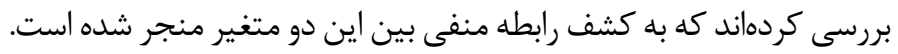

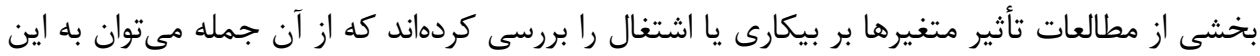

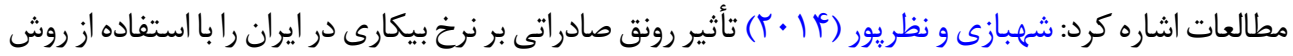

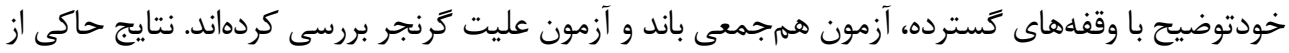

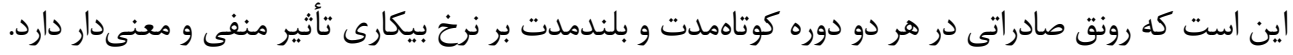

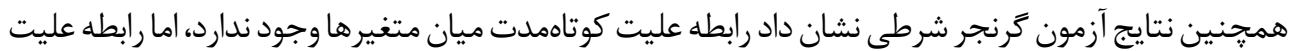

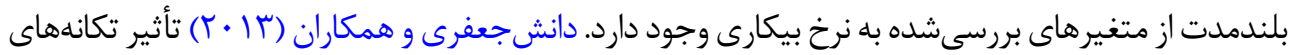

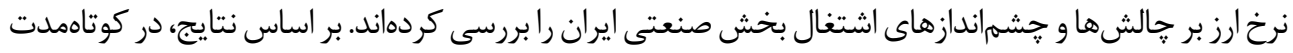

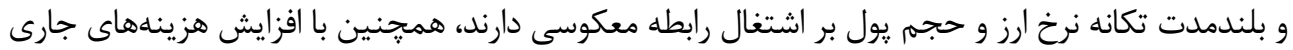

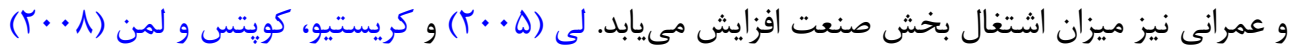

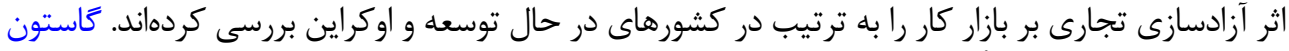

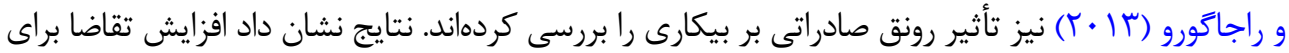

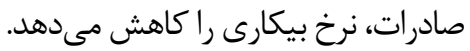

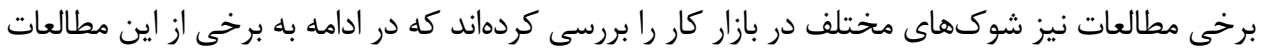

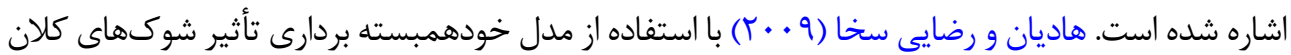

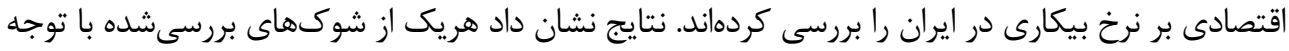




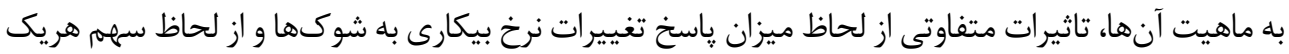

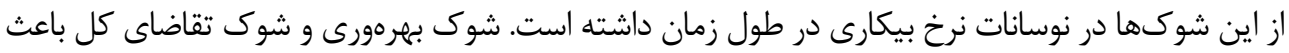

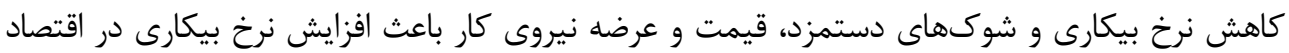

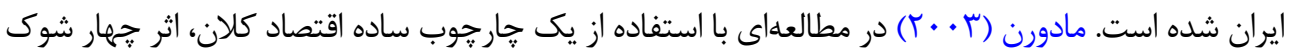

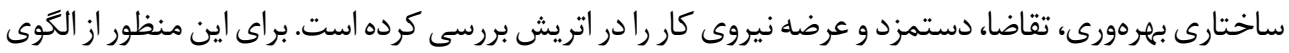

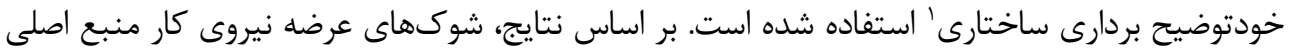

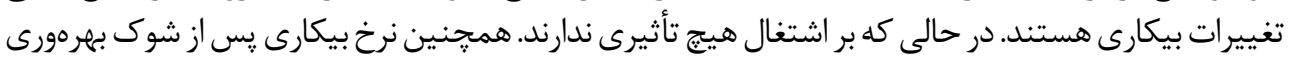

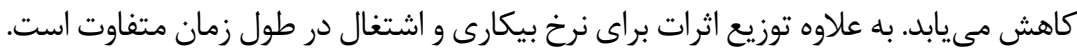

دولادو و جيمنو (99V (19) دلايل اصلى بيكارى در اسيانيا را بررسى كردهاند. نتايج نشان داد بيكارى در اسِانيا

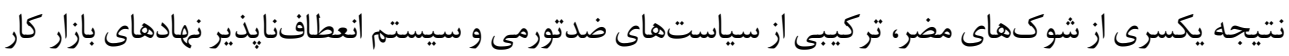

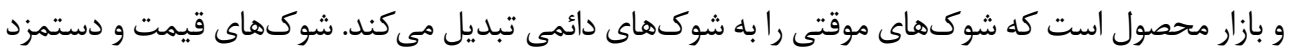

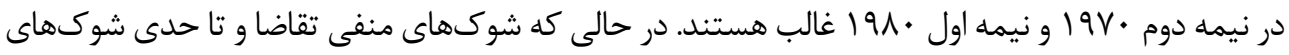

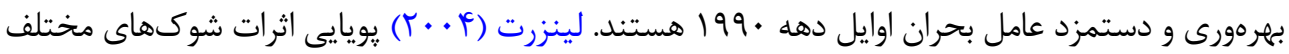

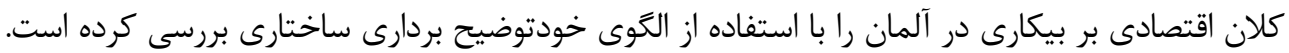

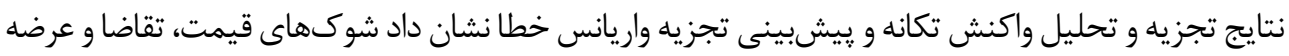

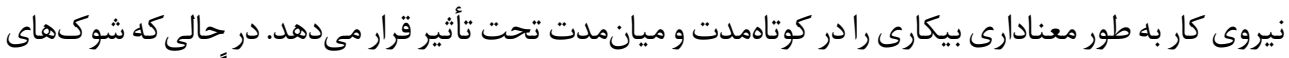

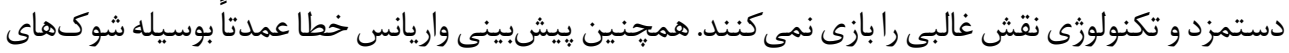

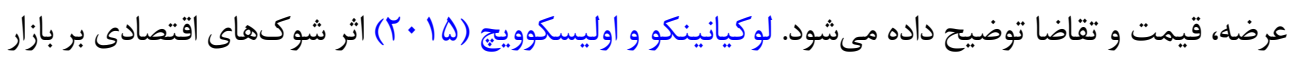

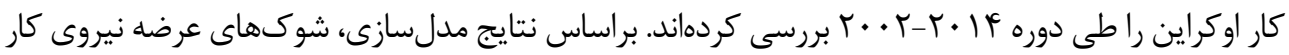

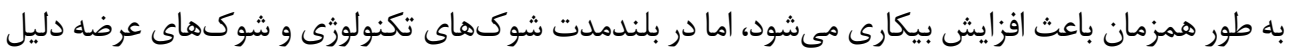

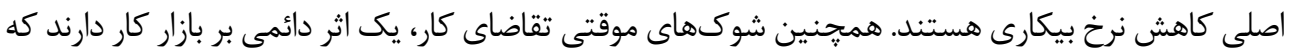

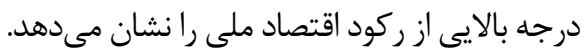

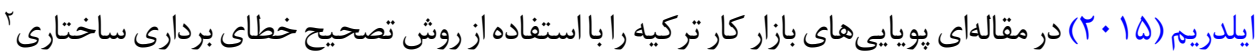

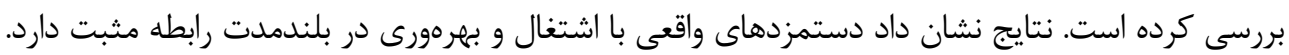

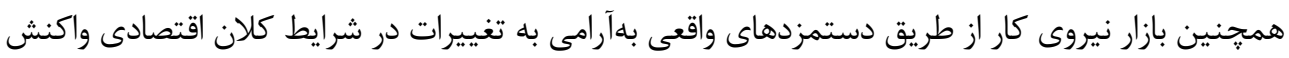

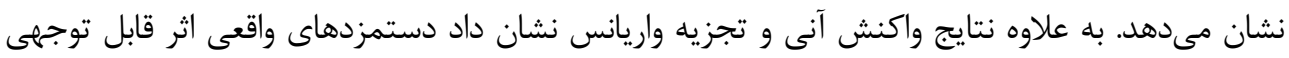

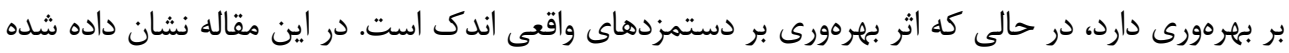

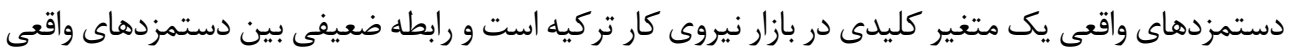

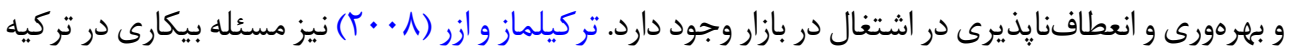
را با استفاده از مدل بECM بررسى كردند و نشان دادند شوكهاى تكنولوزى، دستمزد و عرضه نيروى كار

1. Structural Vector Autoregressive (SVAR)

2. Structural Vector Error Correction Model (SVECM) 


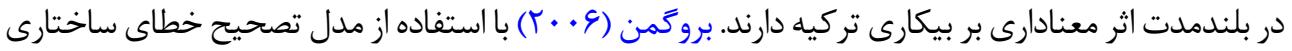

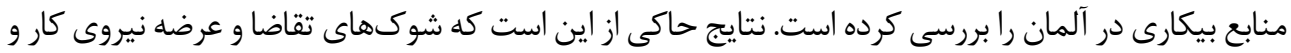

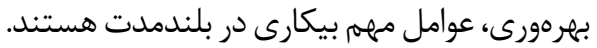

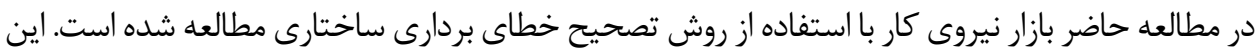

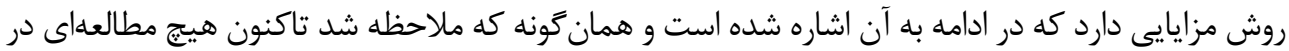

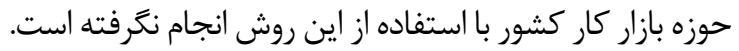

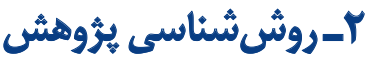

\section{r- - - جار جوب عمومى التّوى تصحيح خطاى بردارى ساختارى}

در ادبيات اقتصادى، هر گونه انحراف مقادير متغيرها از روند بلندمدت مقادي آنادير انتظارى آنها، شوكى ناميده ميشود

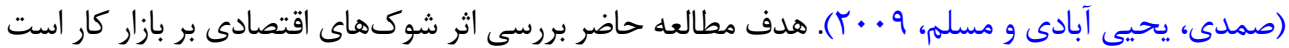

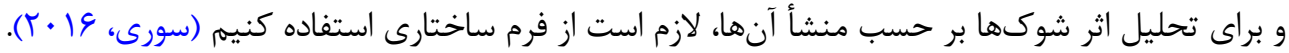

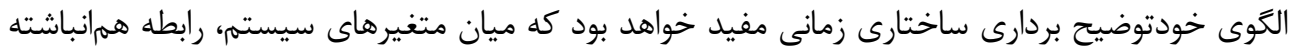

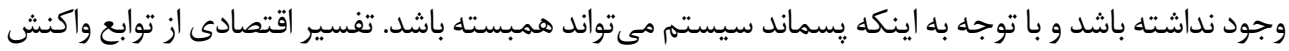

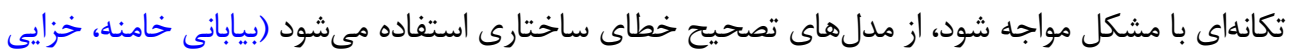

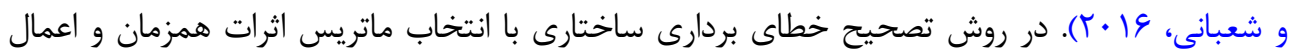

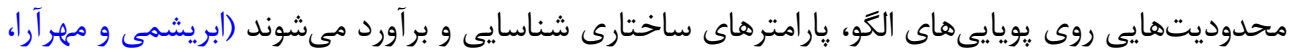

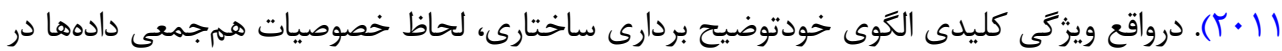

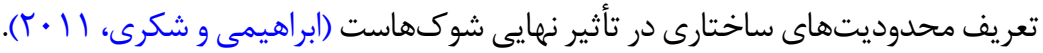
فرم كاهشى استاندارد مدل (VECM(p) به صورت فرمول شماره ا است:

$$
\Delta y_{t}=\alpha \beta^{\prime} y_{t-1}+\Gamma_{1} \Delta y_{t-1}+\ldots . .+\Gamma_{p-1} \Delta y_{t-p+1}+D_{t}+u_{t}
$$

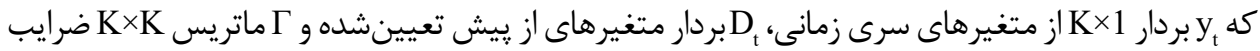

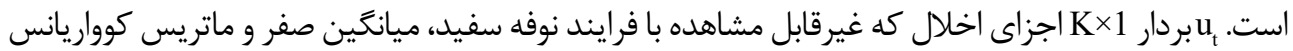

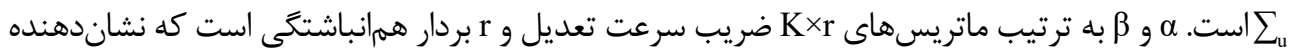

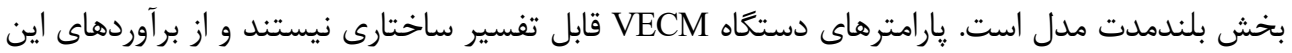

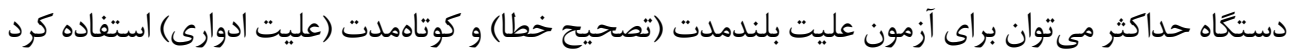

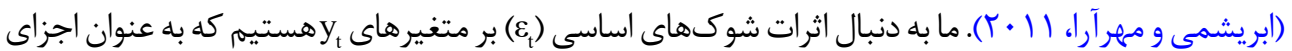

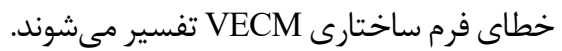


براى بازيابى شوكهاى ساختارى از باقىماندههاى فرم كاهشى تخمين ECM، فرض مىشود باقى ماندهها

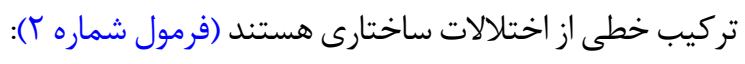

r.

$$
u_{t}=A_{0} \varepsilon_{t}
$$

كه فرض مىشود A يك ماتريس معكوس يذير است (لينزرت، ؟ + . ب). براى تجزيه و تحليل اثر شوكهاى

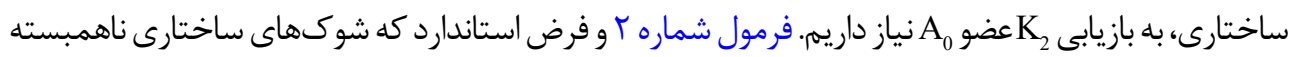

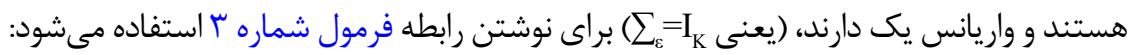

$$
\sum_{u}=A_{0} A_{0}^{\prime}
$$

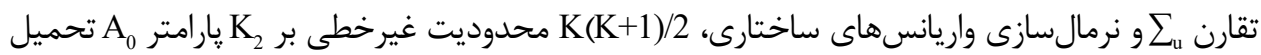

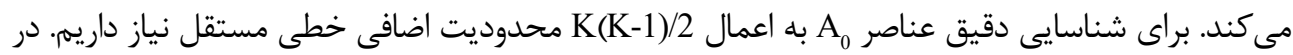

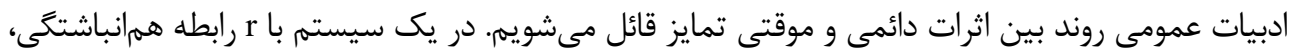

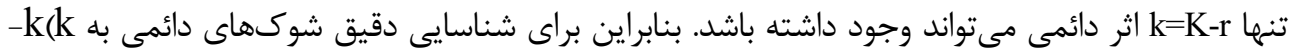

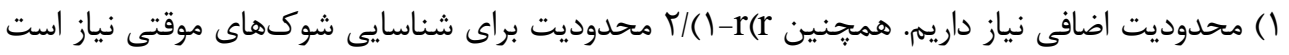

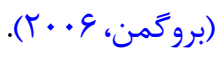

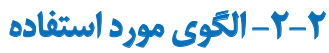

براى ايجاد يك مدل تجربى، از مدل تعديل شده بازار نيروى كار اقتصاد كلان كه اولينبار توسط جاكوبسون و

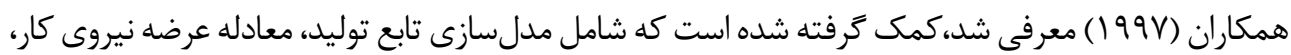

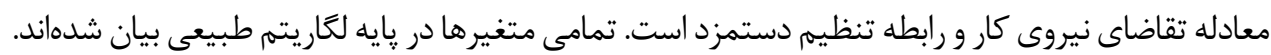
تابع توليد به عنوان رابطه بين ستاده و اشتغال تعريف مىشود (فرمول شماره ؟).

$r g_{t}=\rho e m_{t}+\theta_{t}$

كه rg لعاريتم توليد ناخالص داخلمى واقعى، p بازده نسبت به مقياس، em لعاريتم تعداد شاغلين و متغير روند تصادفى تكنولوزى است كه از يك فرايند كام تصادفى تبعيت مى كند (فرمول شماره هـ).

$\theta_{t}=\theta_{t-1}+e_{t}^{t}$ 


\section{كه e شوك خالص تكنولوزى (بهربورى) است.}

معادله تقاضاى نيروى كار به عنوان رابطه بين اشتغال، دستمزدهاى واقعى و ستاده تعريف مىشود (فرمول

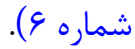

$e m_{t}=-\eta r w_{t}+\lambda r g_{t}+\zeta_{t}$

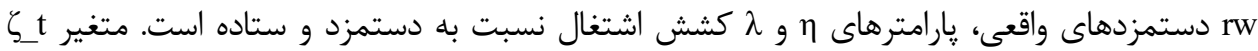

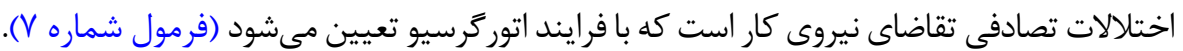

$\zeta_{t}=\varphi \zeta_{t-1}+e_{d}^{t}$

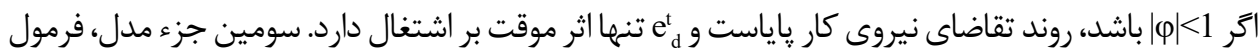

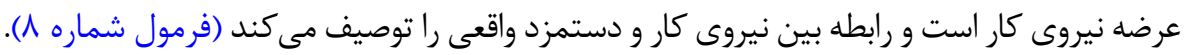

$l_{t}=\pi r w_{t}+\xi_{t}$

روند برونزاى عرضه نيروى كار، ؛ُ، به وسيله فرايند گام تصادفى توصيف مىشود (فرمول شماره 9).

$\xi_{t}=\xi_{t-1}+e_{t}^{s}$

كه نيروى كار و $\pi$ شيب منحنى عرضه نيروى كار و e شوك عرضه نيروى كار است. رابطه تنظيم دستمزد به شكل فرمول شماره • (1است:

$r w_{t}=\delta\left(r g_{t}-e m_{t}\right)+\kappa e m_{t}-\gamma\left(l_{t}-e m_{t}\right)+\varsigma_{t}$

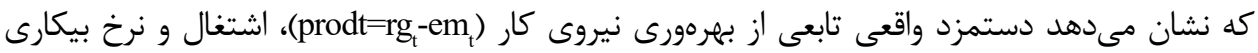

(UR $\left.=1_{t}-e m_{t}\right)$

دارد كه رفتارش را مشخص مى كند (فرمول شماره (1) ). 


$$
\varsigma_{t}=\psi \varsigma_{t-1}+e_{t}^{r w}
$$

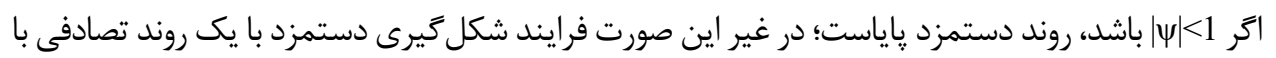

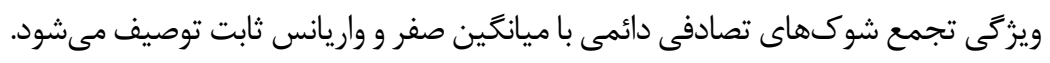

فرض مىشود كه هر جهار شوك خالص، يعنى شوكهاى تكنولوزى، عرضه نيروى كار، تقاضاى نيروى كار و

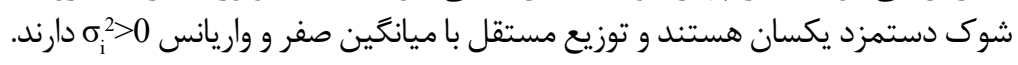

شكل بردارى معادلات \& تا || إ با متغيرهايى كه در تجزيه و تحليل تجربى بازار نيروى كار استفاده شدهاند،

$$
\left[\begin{array}{llll}
1 & 1-p & 0 & 0 \\
-\lambda & 1-\lambda & 0 & \eta \\
0 & 1 & 0 & -\pi \\
-\delta & \kappa & \kappa & 1
\end{array}\right]\left[\begin{array}{c}
r g_{t}-e m_{t} \\
e m_{t} \\
l_{t}-e m_{t} \\
r w_{t}
\end{array}\right]=\left[\begin{array}{c}
\theta_{t} \\
\zeta_{t} \\
\xi_{t} \\
\varsigma_{t}
\end{array}\right]
$$

$$
\text { به صورت زيراست: }
$$

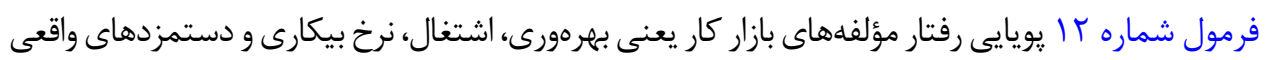

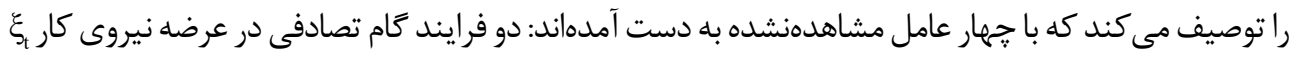

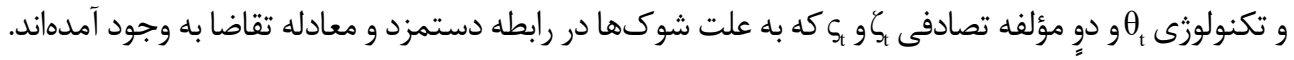

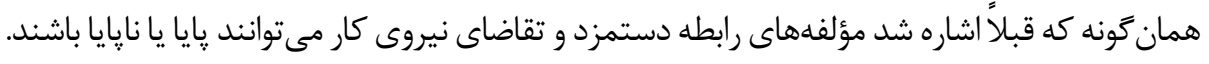

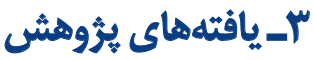

اطلاعات استفادهده در تحقيق حاضر شامل نرخ بيكارى، تعداد شاغلان، دستمزد واقعى و بهرهورى نيروى

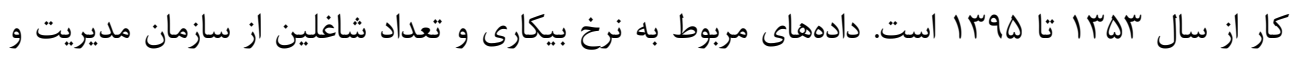

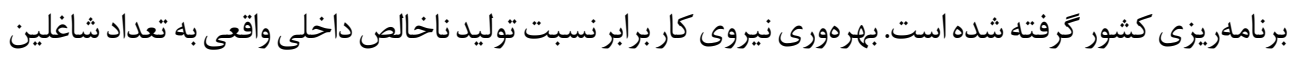

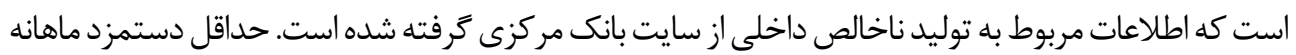

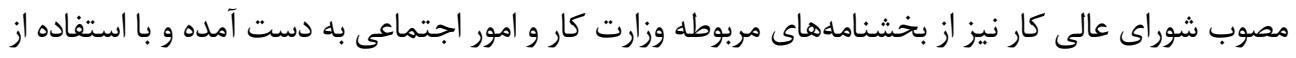

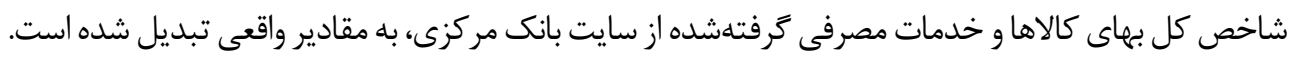
به منظور تخمين الكو، لازم است مانايى متغيرهاى مدنظر بررسى شود. بدين منظور از آزمون ديكىفولر

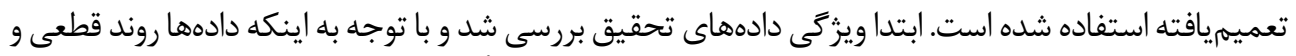

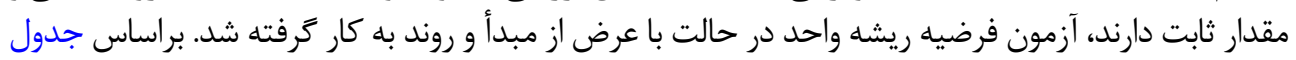

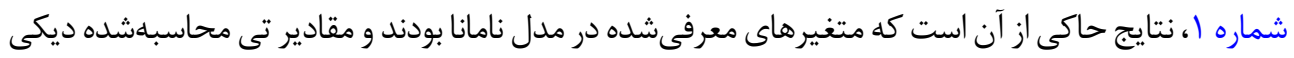

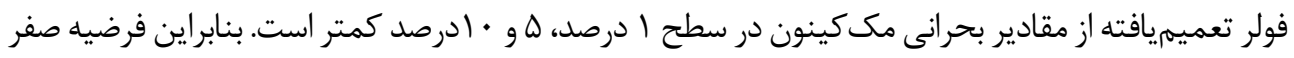


جدول ا.نتايج آزمون ريشه واحد ديكى فولر تعميميافته

\begin{tabular}{|c|c|c|c|c|}
\hline \multicolumn{2}{|c|}{ تفاضل مرتبه اول } & \multicolumn{2}{|c|}{ سطح } & \multirow{2}{*}{ متغير } \\
\hline مقادير بحرانى & آماره مهاسباتى & مقادير بحرانى & آماره محاسباتى & \\
\hline$-t / r q$ & $-1 / 19$ & $-p / r q$ & $-1 / 94$ & (Le) لكاريثم اشتغال) \\
\hline - & $-\Delta / M I$ & te/re & $-Y / A)$ & نُخْ بيكارى(UR) \\
\hline$-p / r e$ & $-F / v A$ & $-p / r e$ & $-r / \cdot F$ & لكاريته بهرهورى(Lprod) \\
\hline - & $-r \mid q)$ & the & $-r / 9 \Delta$ & لكاريتم دستمزد) \\
\hline
\end{tabular}

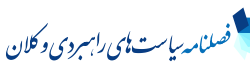

* مقادير بحرانى در سطح ه درصد است.

مأخذ: يافتههاى تحقيق

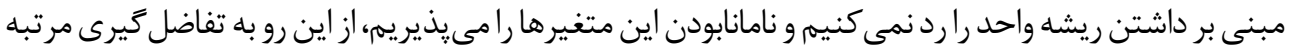

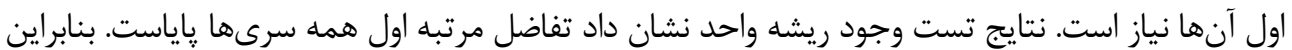

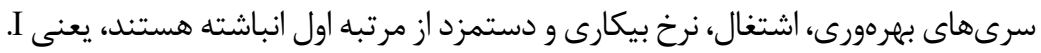

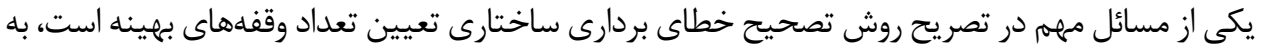

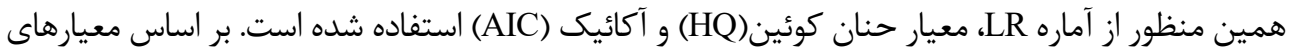

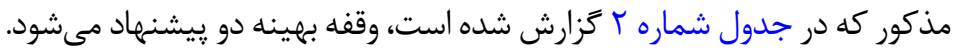

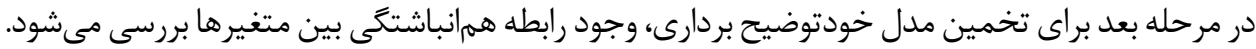

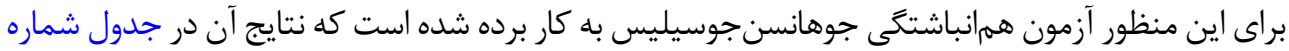

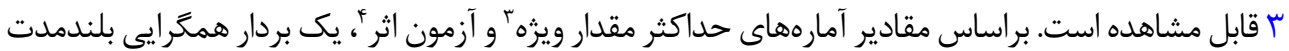
بين متغيرهاى الكو وجود دارد.

رابطه بلندمدت بهدست آمده مى تواند به عنوان رابطه دستمزدهاى واقعى با بهرهورى، اشتغال و بيكارى تفسير

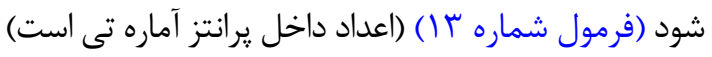

$E T C=L r w-1.26$ Lprod-7.85Le+0.09UR+189.72

(-4.157) (-3.759) (0.783) (3.179)

$L r w=1.26 L$ prod $+7.85 L e-0.09 U R-189.72+E T C$

3. Maximum Eigenvalue

4. Trace Statistic 
جدول r. تعيين تعداد وقفه بيجينه

\begin{tabular}{|c|c|c|c|c|}
\hline HQ & AIC & LR & $\log L$ & وقفه \\
\hline err & $|V /|$ & NA & $-8 V / 91$ & . \\
\hline$-\Delta / \& \Delta$ & $-8 / \cdot 9$ & $r / T r$ & ET/T. & 1 \\
\hline$-8 / . f$ & $-\Delta / V^{f}$ & "TVIFA & er/va & $r$ \\
\hline$-p / 99$ & $n / m e$ & IV/DQ & $V E / T r$ & $r$ \\
\hline
\end{tabular}

جدول r. نتايج آزمون همكرايى

\begin{tabular}{|c|c|c|c|c|c|}
\hline 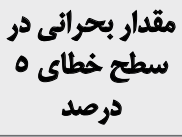 & آماره حداكثر مقدار & 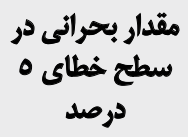 & آماره أزمون اثث & فرض H & H. فرض H \\
\hline $\mathrm{rq} / \Delta \mathrm{s}$ & $M T / E q$ & 8)/1\%q & 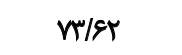 & $\mathrm{R}>0$ & $\mathrm{R}=0^{*}$ \\
\hline$r V / M^{\circ}$ & $19 / 8 A$ & TNPI & $\mathrm{rH} / \mathrm{Rr}$ & $\mathrm{R}>1$ & $\mathrm{R}=1$ \\
\hline $19 / 19$ & $11 / 1$. & reler & $r \cdot / r^{e}$ & $R>2$ & $\mathrm{R}=2$ \\
\hline 1./Kr & NQU & $15 / 19$ & $9 / 81$ & $R>2$ & $R=2$ \\
\hline
\end{tabular}

كه در اين رابطه، بهر هورى با دستمزد رابطه مستقيمى دارد كه نشان مى دهد با افزايش بهرهورى، دستمزدهاى

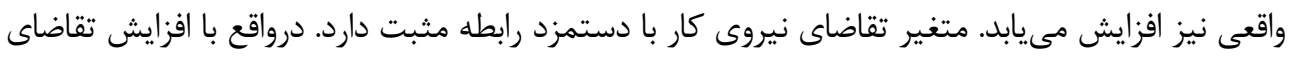

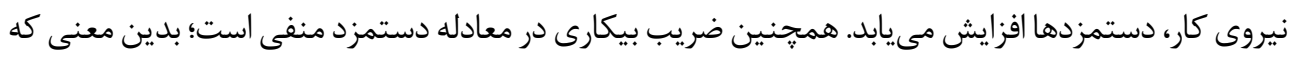

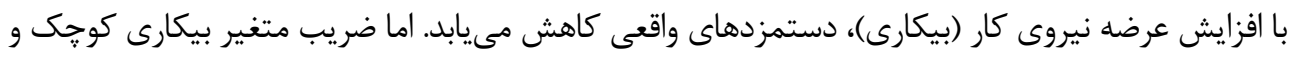

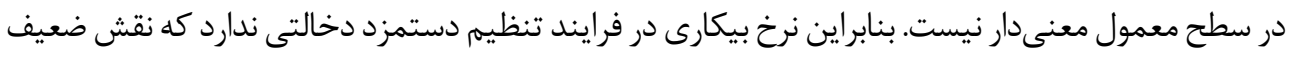

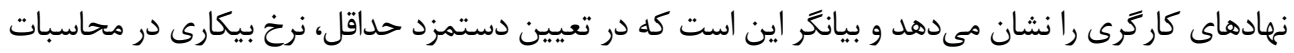

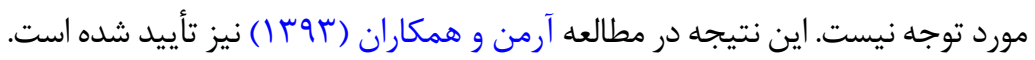

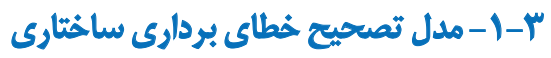

با توجه به اينكه شوكهاى ساختارى مستقيماً قابل مشاهده نيستند، براى تصريح الخوى شكل خلاصهشده

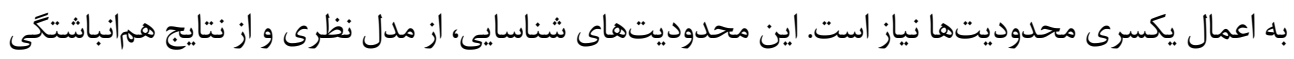




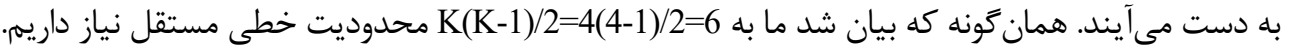

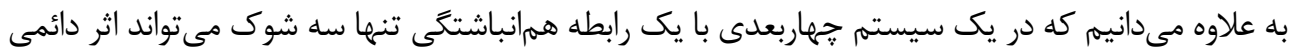

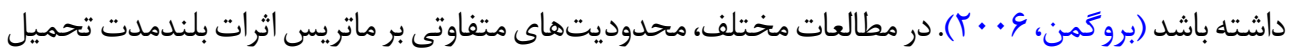
مىشود.

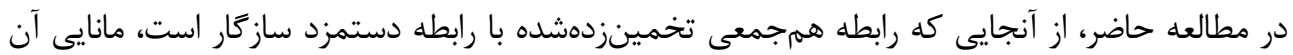

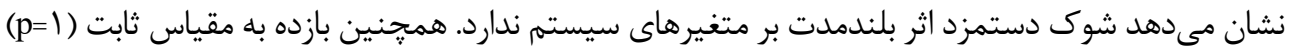

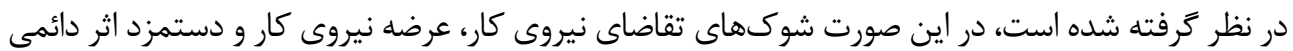

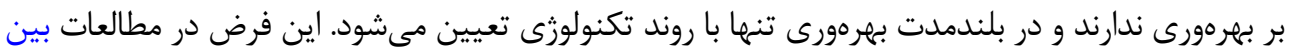

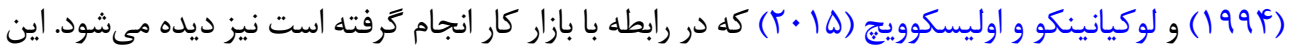

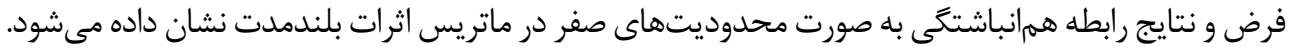
با محدوديتهاى اضافى اعمال شده و تخمين ماتريس اثرات بلندمدت، فرمول شماره f ا | راداريم:

$B^{\prime}=\left[\begin{array}{cccc}0.87 & 0 & 0 & 0 \\ (2.69) & \cdots & \vdots & \vdots \\ 0.00 & 0.00 & 0.06 & 0 \\ (1.68) & (1.69) & (2.89) & \vdots \\ -0.25 & -1.07 & 2.36 & 0 \\ (-2.65) & (-1.58) & (3.30) & \vdots \\ 0.46 & 0.71 & 0.19 & 0 \\ (1.67) & (3.85) & (1.67) & \cdots\end{array}\right]$

.14

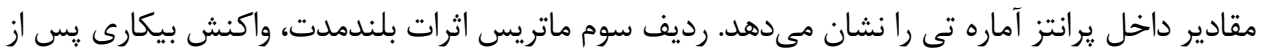

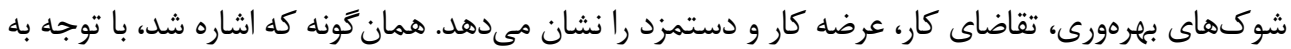

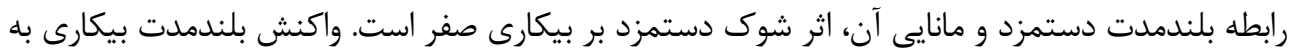

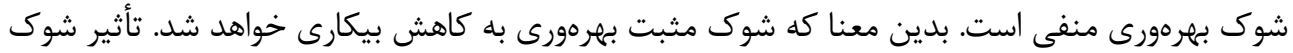

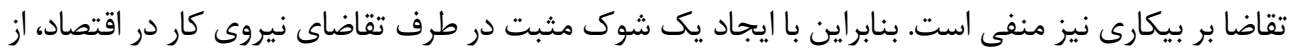

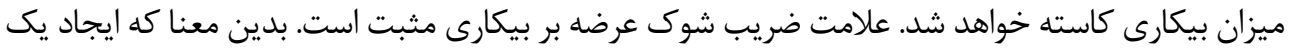

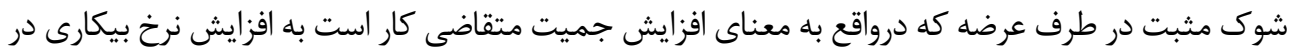

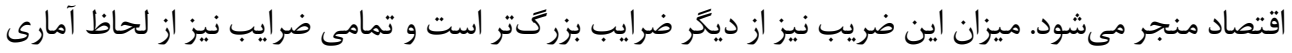
معنادار هستند. 

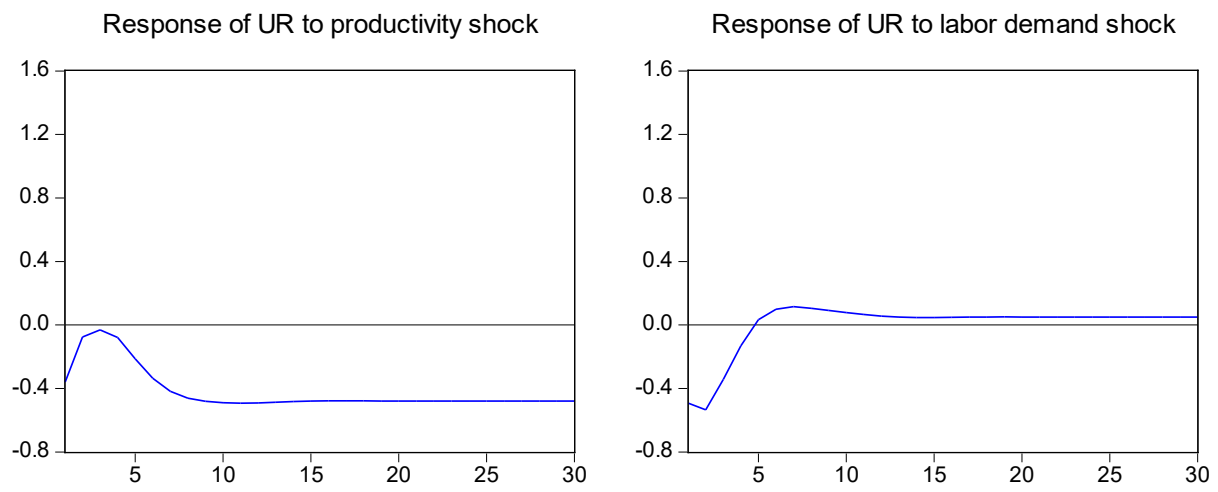

Response of UR to labor supply shock

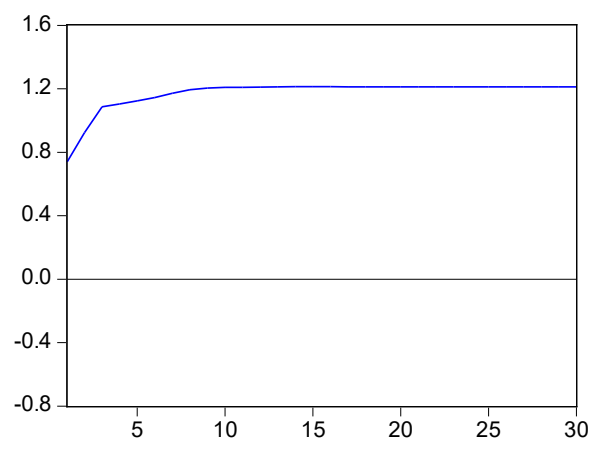

Response of UR to wage setting shock

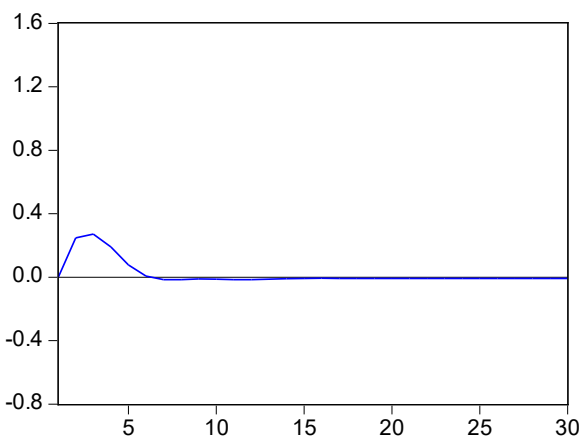

|ct

تصوير r. توابع واكنش آنى متغير بيكارى

"Y-r- تحليل توإي واكثش تكائه

مدل هاى تصحيح خطاى بردارى ساختارى امكان تحليل واكنش تكانه را نيز فراهم مى كنند؛ به اين شكل كه

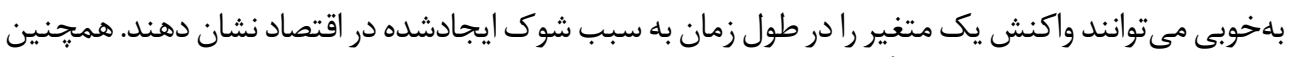

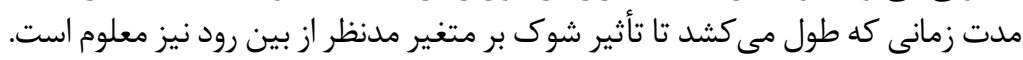

در تصوير شماره ا توابع واكنش تكانه متغير بيكارى به شوكهاى دستمزد، بهرهورى، عرضه و تقاضاى نيروى

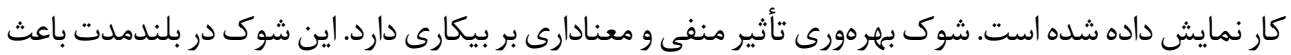

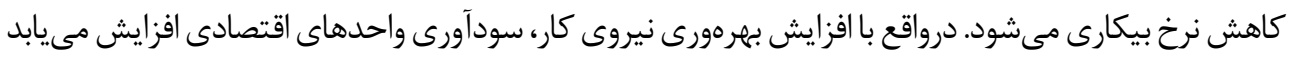

5. Impulse Response Functions 
و بنغاهها به دنبال كسب سود بيشتر اقدام به استخدام نيروى كار بيشترى مى كنند كه اين به معناى كاهش

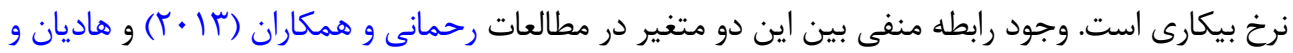

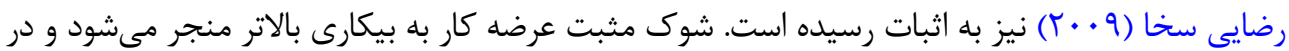

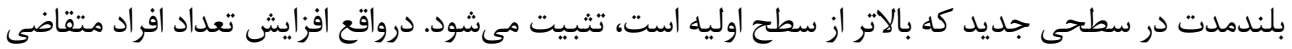

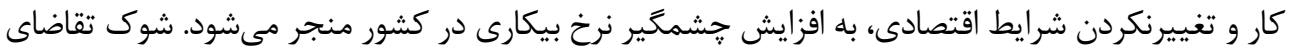

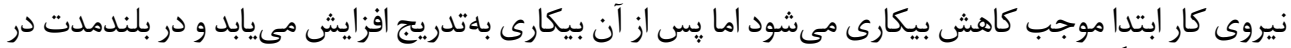

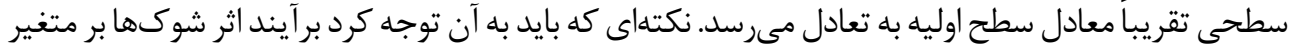

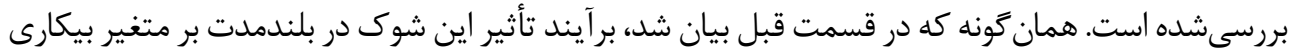

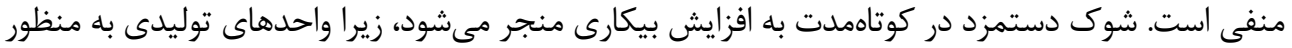

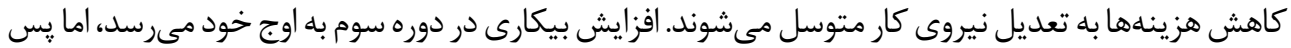

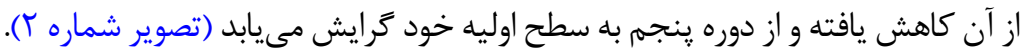

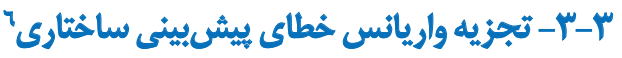

به كمك SFEVD سهمم بى ثباتى هر متغير در مقابل شوك وارده به هريك از متغيرهاى ديخر مدل تعيين

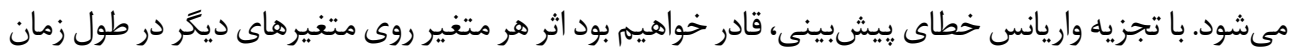

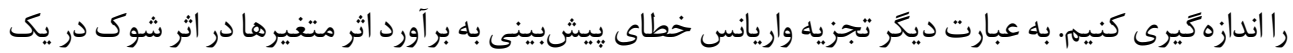

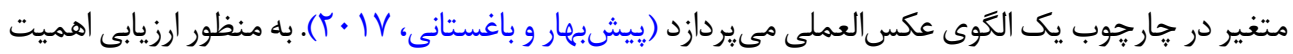

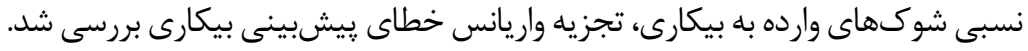

نتايج تجزيه واريانس خطاى ييشبينى بيكارى براى افقهاى مختلف به دست آمده است. بر اساس نتايج،

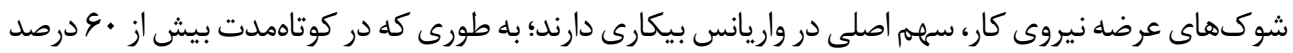

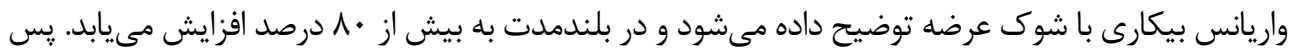

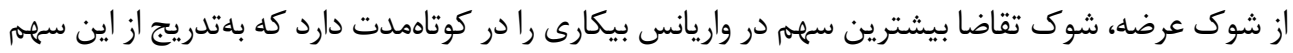

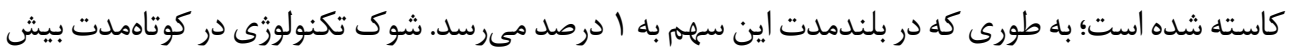

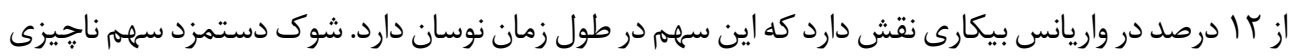

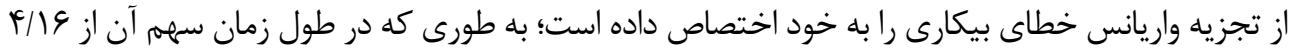
درصد تجاوز نكرده است.

\section{ع-بحث و نتيجليَيرى}

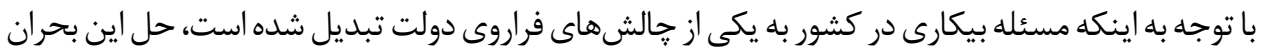

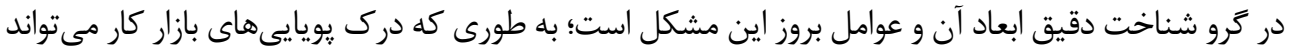

6. Structural Forecast-Error Variance Decomposition (SFEVD) 
در تدوين سياستهاى تعديل نوسانات اشتغال اهميت داشته باشد. بنابراين در اين تحقيق شاخصهاى مؤثر بر

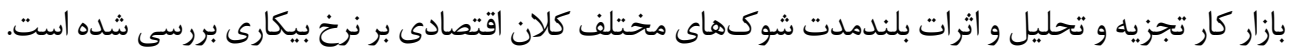

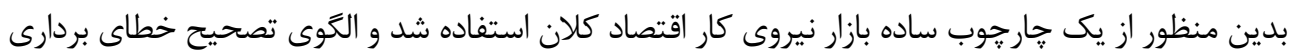

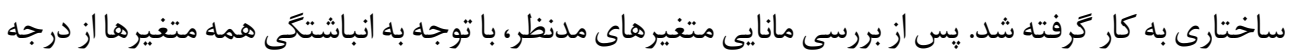

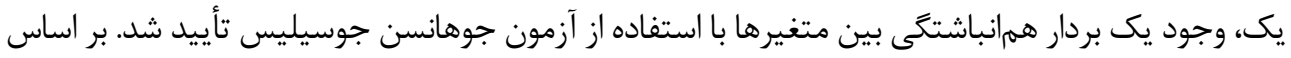

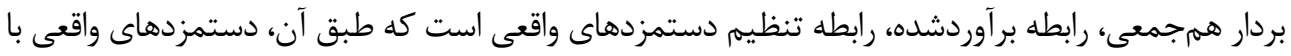

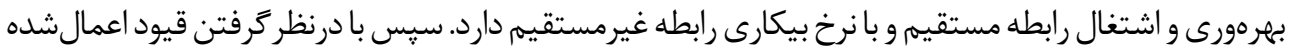

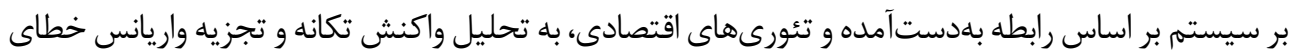

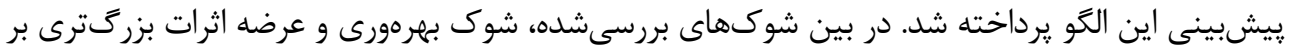

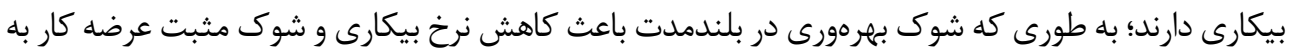

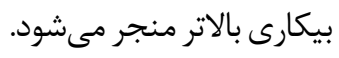

به علاوه بر اساس نتايج تجزيه واريانس خطاى ييشبينى بيكارى، شوك عرضه نيروى كار، بهرهورى و

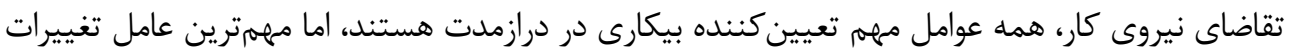

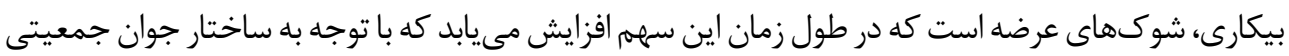

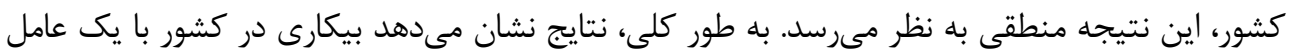

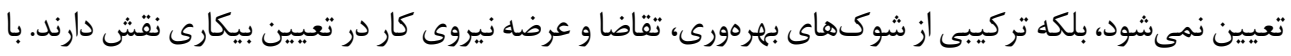

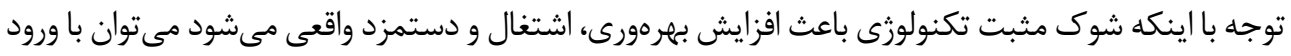

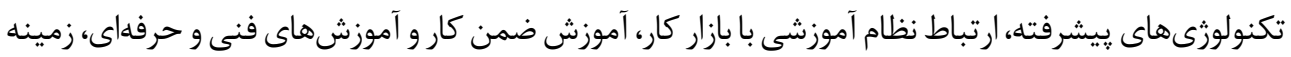

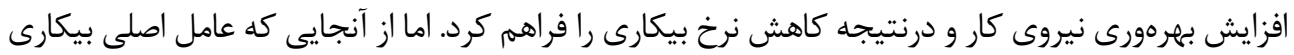

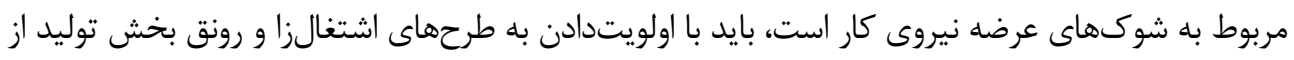
تبعات اين معضل كاست.

مالاحظات اخلاقي

\section{يبروى از اصول اخلاق هيثوهش}

همه اصول اخلاقى در اين مقاله رعايت شده است. شركت كنند

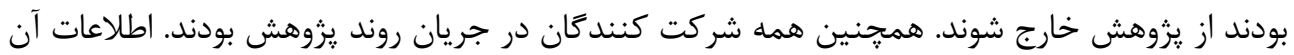

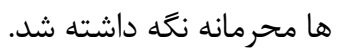

\section{مامي مالى}

اين مقاله حامى مالى ندارد. 


$$
\text { مشاركت نويسيندك }
$$

تمام نويسندگان در طراحى، اجراو نَارش همه بخشهاى يروهش حاضر مشاركت داشتهاند.

$$
\text { تعارض منافع }
$$

بنابر اظهار نويسندگان، اين مقاله تعارض منافع ندارد. 


\section{References}

Abrishami, H., \& Mehrara, M. (2011). [Interaction effects of nominal and true variables in a structural error correction pattern (case study of Iran) (Persian)]. Quarterly Journal of Economic Research, 9: 88-4.

Arman, A., Kofili, V., \& Ghorbannezhad, M. (2014). [Investigating the relationship between minimum wage and unemployment (Persian)]. Quarterly Journal of Applied Economic Studies, 3(12), 236-21.

Bean, C. R. (1994). European unemployment: A survey. Journal of Economic Literature, 33(2), 573- 619.

Biyabani Khamenei, K., Khozai, S., \& Shabani, V. (2016). [Applied econometrics (Persian)]. Tehran: Naghoos Press.

Brüggemann, R. (2006). Sources of German unemployment: a structural vector error correction analysis. Empirical Economics, 31(2), 409-31. [DOI:10.1007/s00181-005-0021-x]

Christev, A., Kupets, O., \& Lehmann, H. (2008). Trade liberalisation and employment effects in Ukraine. Comparative Economic Studies, 50(2), 318-340.

Daneshjafari, D., Sardarshahraki, A., Asnaashari, H., \& Hartami, Y. (2013). [The impact of exchange rate shocks on the challenges and prospects of employment in the industrial sector of Iran (Persian)]. Quarterly Journal of The Macro and Strategic Policies, 1(1), 93-104.

Dolado, J. J., \& Jimeno, J. F. (1997). The causes of Spanish unemployment: A structural VAR approach. European Economic Review, 41(7), 1281-307. [DOI:10.1016/S0014-2921(97)00058-5]

Ebrahimi, M., \& Shokri, N. (2011). [Investigating the effect of macroeconomic variables on stock prices with an emphasis on the role of monetary policy (Persian)]. Quarterly Journal of Economical Modeling, 5(1), 23-45.

Fang, T., \& Lin, C. (2015). Minimum wages and employment in China. IZA Journal of Labor Policy, 4, 22. [DOI: 10.1186/ s40173-015-0050-9]

Feenstra, R. \& Hong, C. (2007). Chinas exports and employment. Cambridge: National Bureau of Economic Research. [DOI:10.3386/w13552]

Gaston, N., \& Rajaguru, G. (2013). How an export boom affects unemployment. Economic Modelling, 30, 343-55. [DOI:10.1016/j. econmod.2012.09.007]

Hadian, E., \& Rezaei Saka, Z. (2009). [The effect of economic shocks on the unemployment rate in Iran (Persian)]. Quarterly Journal of Quantitative Economics, 6(1), 50-27.

Jacobson, T., Vredin, A., \& Warne, A. (1997). Common trends and hysteresis in Scandinavian unemployment. European Economic Review, 41(9), 1781-6. [DOI:10.1016/S0014-2921(96)00027-X]

Lee, E. (2005). Trade liberalization and employment. New York: United Nations Department of Economic and Social Affairs.

Linzert, T. (2004). Sources of German unemployment: Evidence from a structural VAR Model/Die hintergründe deutscher arbeitslosigkeit: Evidenz von einem Strukturellen VAR. Jahrbücher für Nationalökonomie und Statistik, 224(3), 317-36. DOI:10.1515/jbnst-2004-0303]

Lukianenko, I., \& Oliskevych, M. (2015). The effects of shocks on the Ukrainian labor market: SVEC modeling. Procedia Economics and Finance, 27, 311-22. [DOI:10.1016/S2212-5671(15)01002-3]

Maidorn, S. (2003). The effects of shocks on the Austrian unemployment rate - A structural VAR approach. Empirical Economics, 28(2), 387-402. [DOI:10.1007/s001810200137] 
Moghaddam Tabrizi, N. (2005). [A review of the labor market situation in recent years (Persian)]. Ravand, 47, 127-01.

Pishbahar, E., \& Baghestani, M. (2017). [Investigate the economical effects of world food and oil price on macroeconomic variables in Iran (Persian)]. Iranian Journal of Agricultural Economics and Development Research, 48(2), 197-209.

Rahmani, T., Behpour, S., \& Ostadzad A. H. (2013). [An empirical examination of the relationship between productivity and unemployment: Simultaneous equations approach (Persian)]. Journal of Economic Research and Policies, 21(67), 153-70.

Sahbazi, K., \& Nazarpour, Sh. (2014). [Impacts of export boom on unemployment in Iran (Persian)]. Quarterly Journal of Applied Economics Studies,11(3), 159-85.

Samadi, S., Yahya Abadi, A., \& Moallemi, N. (2009). [Analysis of oil price shocks on macroeconomic variables in Iran (Persian)]. Quarterly Journal of Economic Research and Policy, 17(53), 26-5.

Sen, A., Rybczynski, K., \& Van De Waal, C. (2011). Teen employment, poverty, and the minimum wage: Evidence from Canada. Labour Economics, 18(1), 36-47. [DOI:10.1016/j.labeco.2010.06.003]

Souri, A. (2016). [Econometrics (Persian)]. Tehran: Chaponashr.

Türkyllmaz, S., \& Özer, M. (2008). A time series analysis of Turkish unemployment. MIBES Transactions, 2(1), 175-89.

Yıldirım, Z. (2015), The analysis of Turkish labor market with Structural Vector Error Correction Model (SVECM). Ekonomik Yaklasim, 26(94), 57-84. [DOI:10.5455/ey.35602] 